Revista Cientifica do Instituto Agronômico, Campinas

\title{
A ANÁLISE DE SOLO PARA DISCRIMINAR RESPOSTAS Ã ADUBAÇÃO PARA A CULTURA DO MILHO ( $\left.{ }^{(}\right)$
}

B. Van RaiJ, C. T. Feitosa $\left(^{2}\right)$, H. Cantarella, Seção de Fertilidade do Solo, A. P. Camargo ( $\left.{ }^{2}\right)$, Estação Experimental de Piracicaba, A. R. Dechen $\left(^{2}\right)$, Seção de Fertilidade do Solo, S. Auves, Estação Experimental de Monte Alegre do Sul, G. SoRDI, Estação Experimental de Ribeirão Preto, A. A. VeIGA, Estação Experimental de Tietê, M. P. CAMPanA, Estação Experimental de Jaú, A. Petinelli, Estação Experimental de Tatuí, Instituto Agronòmico, e C. NERY, Estação Experimental de Säo Simão, Ministério da Agricultura.

\section{RESUMO}

Diversos parâmetros fornecidos pela análise de solo têm sido usađos no Estado de São Paulo para discriminar as respostas à adubação de culturas. Neste trabalho foi avaliada a eficiência desses parâmetros como critério de interpretação, através de estudos de correlação entre resultados de análise de solo e respostas de milho à adubação com nitrogênio, fósforo e potássio em 25 ensaios. Nenhum critério se revelou eficaz para nitrogênio. O teor de fósforo solúvel em $\mathrm{H}_{2} \mathrm{SO}_{4} 0,05 \mathrm{~N}$ foi eficiente, năo tendo havido melhora apreciável das correlaçōes pela consideração dos teores de matéria orgânica, argila ou pH. O teor de potássio trocável revelou-se eficaz, não tendo sido observada melhoria da correlação pela consideração de cálcio e magnésio ou saturação de potássio. No trabaino sāo apresentadas curvas médias de resposta, bem como as eficiências fertilizantes de nitrogênio, fósforo e potássio, em conjunto para o primeiro elemento e separadas em grupos de acordo com a análise de terra para os dois outros nutrientes.

\section{INTRODUÇÃO}

A interpretação da análise de solo para fins de recomendação de adubação tem sido objeto de muitos trabalhos nas últimas décadas. Nesse período houve um avanço considerá- vel em vários aspectos relacionados ao assunto, incluindo obtenção de resultados experimentais, métodos analíticos e filosofia de interpretação.

E de grande importância para a interpretação da análise de solo o

(1) Trabalho apresentado na XIV Reuniāo Brasileira de Fertilidade do Solo, realizada em Cuirbá (MT), de 14 a 19 de julho de 1980 . Recebido para publicaçăo a $1 .^{\circ}$ de julho de 1980 .

(2) Com bolsa de suplementação do CNPq. 
Vol. 40 , Art. n. ${ }^{\circ} 6$

trabalho clássico de BRAY (2). O autor desenvolveu conceitos de grande utilidade, destacando-se a idéia de considerar os elementos fósforo $\mathrm{e}$ potássio como relativamente imóveis e o nitrogênio como relativamente móvel. No caso dos dois primeiros, considerou que sua disponibilidade é elástica, devido às grandes quantidades presentes, havendo no solo muito mais do que o suficiente para uma cultura, mesmo em solos deficientes. Outra idéia, defendida no seu trabalho, é a utilização da produção expressa em porcentagem nos estudos de correlação com análise de terra, com o que são minimizados os efeitos de diferentes produtividades, entre ensaios na resposta das culturas à adubação.

Existe grande número de trabalhos importantes na literatura internacional sobre interpretação da análise de terra. Dentre eles, merecem destaque o trabalho de revisão de FITTZ \& NELSON (6) sobre uso de análise de terra para recomendar adubação e calagem, o de ROUSE (25), apresentando a teoria de calibração de análise de terra empregada no Estado de Alabama, o de RIS \& LUIT (23), descrevendo o sistema de estabelecimento de recomendaçóes da adubação com base na análise de terra na Holanda e, também, o livro sobre análise de solo e plantas editado por WALSH \& BEATON (32), contendo inúmeras informações recentes sobre toda a sistemática de execução e interpretação da análise de solos.

Em São Paulo, os índices de interpretação de análise de terra mais difundidos foram os publicados por CATANI et alii em 1955 (4), no "Boletim 69": não havia ainda dados experimentais suficientes e o critério de divisão em classes de teores altos, médios e baixos foi bastante influenciado pela ocorrência natural dos teores de nutrientes em solos do Estado. Na ocasião foi dada uma interpretação para teores de fósforo, potássio, cálcio, magnésio, nitrogênio e matéria orgânica.

Posteriormente, foram realizados trabalhos correlacionando resultados de respostas de culturas à adubação em ensaios de campo, com os teores de nutrientes no solo. Além disso, foram estabelecidos critérios de interpretação de análise com a definição de classes de resposta à adubação. MIRANDA (15) apresentou uma revisão sobre interpretação de análise de terra para milho. O método de extração de fósforo com $\mathrm{H}_{2} \mathrm{SO}_{4}$ $0,05 \mathrm{~N}$ não foi considerado satisfatório. Para interpretação de análises, são sugeridos como critérios para fósforo e nitrogênio, o $\mathrm{pH}$ e os teores de fósforo e matéria orgânica do solo, em tabelas de tripla entrada. Para potássio, os critérios foram os teores de potássio e cálcio + magnésio, em tabelas de dupla entrada. A eficiência das tabelas de adubação assim preparadas foi demonstrada por MIRANDA \& JORGE (14) comparando o retorno econômico calculado pela adubação da tabela e do tratamento sem adubação, e por MIRANDA et alii (16), comparando em campos de demonstração a adubação recomendada a partir da tabela, com a adubação do agricultor e com os tratamentos sem adubo.

Para algodão, há trabalhos realizados por três equipes diferentes neste Estado. VERDADE et alii (29) mostraram haver correlação entre resposta à aplicação de fósforo para a cultura do algodão $\mathrm{e}$ os teores do 
elemento no solo extraído com $\mathrm{H}_{2} \mathrm{SO}_{4} 0,05 \mathrm{~N}\left(\mathrm{r}^{2}=0,50\right)$. Da mesma maneira, FREITAS et alii (7) mostraram haver correlação significativa entre respostas à adubação potássica $\mathrm{e}$ os teores de potássio no solo $\left(\mathrm{r}^{2}=0,49\right)$. FUZATTO \& CAVALERI (8) encontraram correlações para resposta a fósforo com teores de $\mathrm{P}$ no solo e a acidez, sendo a maior parte da variação das respostas explicada por uma expressão de acidez (cerca de $25 \%$ ) e apenas cerca de $7 \%$ pela relação com fósforo. Para potássio, FUZATTO \& FERRAZ (10) obtiveram excelente correlação múltipla para aumentos de produção de algodão pela adubação potássica e parâmetros de solos com um coeficiente de determinação de 0,65 , onde a relação $\mathrm{Ca} / \mathrm{K}$ apresentou um coeficiente parcial de 0,60 e o teor de $\mathrm{K}$, apenas 0,23 .

Cabe aqui uma observação sobre a maneira de correlacionar as variáveis em estudos de correlação entre respostas à adubação e teores de solo. A relação dificilmente será linear, e esta provavelmente é uma das razões para os coeficientes de correlação um pouco mais baixos obtidos por FUZATTO \& CAVALERI (8) para $\mathrm{P} e$ FUZATTO \& FERRAZ (9) para $\mathrm{K}$. Note-se também que FREITAS et alii (7) estabeleceram correlação com $1 / K$, ao invés de $K$, o que consiste na realidade em transformar uma correlação curvilínea em linear. Daí, poder-se levantar a hipótese que parte do efeito favorável da relação com $\mathrm{Ca} / \mathrm{K}$ obtida por FUZATTO \& FERRAZ (10) se deva à influência de retificação dos dados pelo termo 1/K. RAIJ (20) obteve correlações significativas entre respostas à adubação potássica para feijão, cana-de- -açúcar e algodão, as três culturas consideradas em conjunto, e $1 / \mathrm{K}$ $\left(\mathrm{r}^{2}=0,58\right)$, e RAIJ \& MASCARENHAS (21) obtiveram correlações similares para soja, considerando $1 / \mathrm{K}\left(\mathrm{r}^{2}=0,30\right)$ e $1 / \mathrm{P}\left(\mathrm{r}^{2}=0,42\right)$.

Outra observação diz respeito à magnitude do coeficiente de determinação, que depende, de um lado, da associação existente entre as variáveis, mas, também, da distribuição dos dados experimentais disponíveis que devem, de preferência, cobrir a faixa de teores desde baixos até altos. Isso em geral é difícil de obter, pois não é fácil conseguir ensaios bem distribuídos. Quando a distribuição é boa, os coeficientes de determinação podem aumentar muito, como foi constatado por MARINHO \& ALBUQUERQUE (13), que obtiveram um valor de $\mathbf{r}^{2}=0,86$ para a correlação entre resposta a fósforo e o teor de elemento no solo para cana-de-açúcar.

A obtenção de correlações entre respostas às adubações é, sem dúvida, 0 passo inicial para o estabelecimento de critérios de interpretação de análise, embora critérios semi-empíricos possam ser utilizados com uma relativa eficiência sem que as correlações tenham sido obtidas. FUZATTO et alii (11) adotaram um sistema semelhante ao já descrito para milho, estabelecendo a priori classes de resposta à adubação do algodoeiro e prepa: rando tabelas de dupla entrada. Utilizaram os teores de $\mathrm{P}$ e $\mathrm{N}$ no solo para as classes de resposta à adubação nitrogenada, os teores de $\mathrm{P}$ e a acidez (produto da saturação em bases pelo pH) para a adubação fosfatada, e os teores de $\mathrm{K}$ e $\mathrm{Ca}$ para a adubação potássica. As classes de resposta permitiram separar ensaios de maiores respostas com maior eficiência para 
fósforo e potássio. Utilizando ensaios mais recentes, SILVA et alii (27) mostraram que o critério para potássio confirmou a sua eficiência, porém não foi possível estabelecer critério para adubação nitrogenada.

As tabelas de dupla ou tripla entrada, principalmente se preparadas de maneira semi-empírica, apresentam um inconveniente: a interpretação da análise de terra torna-se complexa e o técnico que utiliza a tabela dificilmente perceberá o parâmetro dado pela análise de solo que mais afeta a resposta à adubação. Em alguns casos, a alternativa mais simples, de só usar o teor do elemento no solo, pode ser suficiente. Para algodão, SILVA (26) obteve um coeficiente de determinação de 0,55 em uma correlação múltipla da resposta do algodoeiro à adubação potássica com os teores de $\mathrm{K}$ no solo e a relação $(\mathrm{Ca}+\mathrm{Mg}) / \mathrm{K}$, enquanto, para os mesmos ensaios, pode-se calcular um coeficiente de determinação de 0,64 , usando apenas $1 / \mathrm{K}$ como parâmetro de solo e a produção relativa para indicar a resposta a potássio. Para soja, MASCARENHAS et alii (12), usando tabelas de dupla entrada com $\mathrm{pH}$ e $\mathrm{P}$ no solo, conseguiram uma discriminação boa das respostas para fósforo, mas não foi possível discriminar, através da análise de solo, as respostas a potássio. Com os mesmos ensaios, RAIJ \& MASCARENHAS (21) conseguiram, usando apenas teores de $\mathbf{P}$ e $\mathbf{K}$ do solo, criar classes de resposta para os dois elementos que permitiram discriminar as respostas a ambos.

Uma etapa subsequiente na interpretação da análise de terra, é definir os critérios de delimitação de classes de resposta. No Alabama, os limites de classes de teores no solo são relacionados à produção relativa, ou produção sem a aplicação do nutriente expresso em porcentagem (25). Um sistema similar foi introduzido por RAIJ (20) e RAIJ \& MASCARENHAS (21) em São Paulo e por MARINHO \& ALBUQUERQUE (13) em Alagoas.

CATE JR. \& NELSON (5) difundiram no Brasil uma maneira de determinar um limite crítico, com a criação de duas classes de teores, de alta e baixa probabilidades de resposta. Em São Paulo, o método de limite crítico não chegou a ser empregado na construção de tabelas de adubação com base na análise de terra.

Neste trabalho é apresentado um estudo dos critérios que vêm sendo empregados para interpretar análise de solo para nitrogênio, fósforo e potássio, visando recomendações de adubação com esses três nutrientes. Foram utilizados os resultados experimentais de 25 ensaios de milho obtidos em dois anos agrícolas.

\section{MATERIAL E METODOS}

Foram conduzidos 26 ensaios com milho HMD 79/74, em estações experimentais do Instituto Agronômico e na Estação Experimental de São Simão, do Ministério da Agricultura. Os ensaios foram numerados de 1 a 26 . O de número 3 foi perdido, restando, pois, 25.

De cada local de ensaio foi retirada uma amostra composta do solo e analisada. Nos ensaios de números $4,5,9,10,11,15,16$ e 18 , foi feita calagem visando neutralizar o alumínio trocável. Nesses casos, retirou-se uma nova amostra composta 
por ocasião da instalação do ensaio, que foi a considerada neste trabalho. As amostras foram analisadas, obtendo-se os teores de matéria orgânica, argila, cálcio, magnésio, alumínio, fósforo e potássio e o $\mathrm{pH}$, empregando os métodos descritos por RAIJ \& ZULLO (22).

Os solos foram classificados de acordo com o critério da Comissão de
Solos (in BRASIL, 1) nos casos de Tietê, Jaú, Tatuí, São Simão e Capão Bonito. Para as demais estações experimentais, consideraram-se os levantamentos detalhados de OLIVEIRA et alii (19) para Itararé, ROTTA et alii (24) para Monte Alegre do Sul e OLIVEIRA \& MONIZ (18) para Ribeirão Preto. Os detalhes são os seguintes:

\section{Estação \\ Experimental}

Tietê

Jaú

Tatuí

Ribeirão Preto

$6,7,8(74 / 75)$,

$22(75 / 76)$

São Simão

9, $10(74 / 75)$

$11(74 / 75)$

Capão Bonito

$12,13(74 / 75)$

$14(74 / 75)$

$20(75 / 76)$

Itararé ano agrícola
Número do ensaio e

$1,2(74 / 75), 23(75 / 76)$

$3(74 / 75), 24(75 / 76)$

$5(74 / 75), 21(75 / 76)$

Latossolo Vermelho-Escuro orto

Latossolo Roxo distrófico unidade Quadras

Latossolo Roxo eutrófico, unidade Ribeirão Preto

Latossolo Vermelho-

-Escuro, textura média

Latossolo Roxo

Latossolo Vermelho-Escuro orto

Podzólico Vermelho-Amarelo

Latossolo Vermelho-Escuro orto

Solo com horizonte B câmbico, unidade Coruja 
Monte Alegre do Sul
Podzólico Vermelho-Amarelo, unidade Monte Alegre

$18(74 / 75)$

$26(75 / 76)$
Podzólico Vermelho-Amarelo, unidade Ouro Verde

Podzólico Vermelho-Amarelo, unidade Pau d'Alho
Os ensaios foram instalados com os tratamentos distribuídos em blo$\cos$ ao acaso. Procurou-se obter curvas de respostas para cada nutriente em presença de doses adequadas dos demais nutrientes.
Nó plantio feito em outubro de 1974, correspondente ao ano agrícola $1974 / 75$, os tratamentos, em quilograma/hectare, foram os seguintes:

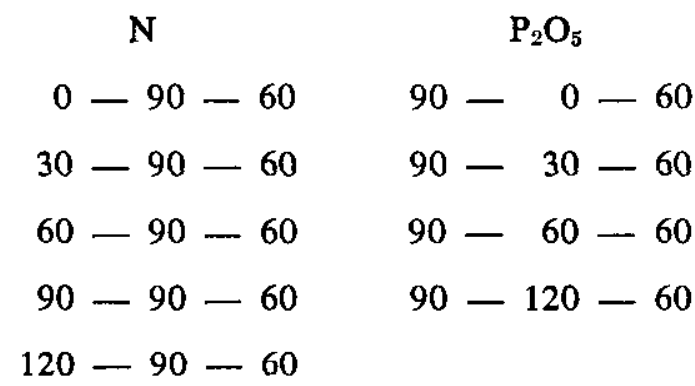

Os canteiros tiveram cinco linhas de $5 \mathrm{~m}$ de comprimento com cinco plantas por metro linear após o desbaste. Os adubos, sulfato de amônio, superfosfato simples e cloreto de potássio, previamente misturados, foram aplicados no sulco de plantio, cerca de $5 \mathrm{~cm}$ abaixo e ao lado das sementes. Um terço do nitrogênio foi aplicado no plantio e dois terços em cobertura, cerca de seis semanas após. O ensaio teve três repetições. Foram colhidas apenas as três linhas centrais.

Em 1975/76 foram introduzidas modificações no esquema experimental, tendo-se feito quatro repetições, incluindo zinco, aplicado apenas uma dose fixa de nitrogênio no plantio e as doses indicadas em cobertura. Os canteiros foram aumentados para quatro linhas de $10 \mathrm{~m}$, colhendo-se as duas centrais. Os tratamentos, em quilograma/hectare, foram os seguintes: 


$\begin{array}{ccc}\mathbf{N}-\mathbf{P}_{2} \mathbf{O}_{5}-\mathbf{K}_{2} \mathbf{O} & \mathbf{Z n} & \mathbf{N} \text { em cobertura } \\ \mathbf{n o} \text { plantio } & 5 & 0 \\ 10-80-50 & 5 & 40 \\ 10-80-50 & 5 & 80 \\ 10-80-50 & 5 & 120 \\ 10-80-50 & 5 & 80+40 \\ 10-80-50 & 5 & 80 \\ 10-0-50 & 5 & 80 \\ 10-40-50 & 5 & 80 \\ 10-120-50 & 5 & 80 \\ 10-80-0 & 0 & 80 \\ 10-80-50 & & \end{array}$

Os dados de cada experimento foram submetidos à análise de variância, efetuando-se a comparação entre as médias de tratamentos pelo teste de Duncan (in 28).

Foram calculadas correlaçóes entre respostas às adubações e parâmetros fornecidos pela análise de solo. Nas correlações, utilizou-se a chamada "produção relativa" ou produção expressa em porcentagem, que reflete a produção obtida com a omissão do nutriente na adubação. Para calcular a produção relativa, foram consideradas como $100 \%$ as produções obtidas respectivamente com as doses 90 , 90 e 60 de $\mathrm{N}, \mathrm{P}_{2} \mathrm{O}_{5}$ e $\mathrm{K}_{2} \mathrm{O}$ no primeiro grupo de ensaios e 80,80 e 50 de $\mathrm{N}, \mathrm{P}_{2} \mathrm{O}_{5}$ e $\mathrm{K}_{2} \mathrm{O}$ no segundo grupo de ensaios.

Para fósforo e potássio, com base na equação ajustada aos dados experimentais, foram estabelecidos limites de classes de teores definidns como muito baixos, baixos, médios e altos. Os teores que limitam essas classes correspondem respectivamente a produções relativas de 70,90 e $100 \%$.

Os ensaios foram separados de acordo com as classes de teores de potássio ou fósforo. Como os ensaios dos dois anos não apresentaram os mesmos níveis de aplicação de nutrientes, utilizou-se uma aproximação para calcular as curvas de resposta, dentro de cada classe de teor no solo. Utilizando todos os resultados, para cada dose e dos dois anos de aumentos de produção em relação à dose zero, ajustou-se a equação do $2 .^{\circ}$ grau aos dados experimentais. Foram estabelecidas, assim, as curvas de resposta a fósforo e potássio, para as diversas classes de teores dos nutrientes no solo. Para nitrogênio, foi calculada uma curva de resposta média para todos os ensaios.

Além das curvas de resposta, foram construídos gráficos indicando a quantidade de milho, em quilograma/ hectare, correspondente a cada quilograma de nutriente aplicado, acompanhando doses crescentes de aplicação. 
Vol. 40 , Art. n. ${ }^{\circ} 6$

\section{RESULTADOS E DISCUSSÃO}

\subsection{Resultados experimentais}

No quadro 1, são apresentados os resultados de análise dos solos dos 25 locais utilizados na experimentação. As amostras foram retiradas antes da instalação dos ensaios, e após a calagem, quando esta foi empre- gada. De maneira geral, há uma variação bastante ampla naquelas variáveis que poderiam afetar a resposta às adubações com nitrogênio, fósforo $\mathrm{e}$ potássio, segundo os critérios correntemente em uso para interpretar análise de solo.

Nos quadros 2 e 3 são apresentados os resultados dos 17 ensaios conduzidos no ano agrícola 1974/75.

QUADRO 1 - Resultados de análise de amostras de solos coletadas antes da instalação dos ensaios

\begin{tabular}{|c|c|c|c|c|c|c|c|c|c|c|}
\hline $\begin{array}{c}\text { Ensaio } \\
n^{\circ}\end{array}$ & Argila & $\begin{array}{l}\text { Matéria } \\
\text { orgânica }\end{array}$ & $\mathrm{P}$ & $\mathrm{pH}$ & $\mathrm{Al}$ & $\mathrm{Ca}$ & $\mathrm{Mg}$ & $\mathrm{K}$ & СТC & V \\
\hline & $\mathrm{g} / 100 \mathrm{~g}$ & $\mathrm{~g} / 100 \mathrm{~cm}^{3}$ & $\mu \mathrm{g} / \mathrm{cm}^{3}$ & " & $\therefore-$ & meq $/ 1$ & $0 \mathrm{~cm}^{3}$ & de ter & $\mathrm{rra}-$ & $\%$ \\
\hline 1 & 14 & 1,5 & 14,1 & 5,5 & 0,1 & 2,3 & 0,5 & 0,25 & 4,3 & 72 \\
\hline 2 & 16 & 1,6 & 5,4 & 5,7 & 0,0 & 2,6 & 0.6 & 0,14 & 4,5 & 73 \\
\hline 4 & 35 & 2,1 & 23,5 & 5,7 & 0,0 & 2,0 & 0,5 & 0,21 & 4,7 & 57 \\
\hline 5 & 63 & 3,0 & 5,2 & 5,4 & 1,0 & 3,5 & 0,9 & 0,46 & 10,3 & 48 \\
\hline 6 & 63 & 4,8 & 2,2 & 5,7 & 0,0 & 4,6 & 1,9 & 0.14 & 10,4 & 64 \\
\hline 7 & 66 & 4,9 & 2,9 & 5,8 & 0,0 & 7,3 & 2,0 & 0,35 & 13,4 & 72 \\
\hline 8 & 66 & 5,0 & 2,0 & 5,9 & 0,0 & 5,2 & 2,2 & 0,17 & 12,4 & 61 \\
\hline 9 & 16 & 1,8 & 2,0 & 6,0 & 0,0 & 1,0 & 1,0 & 0,07 & 4,1 & 51 \\
\hline 10 & 30 & 2,4 & 1,8 & 5,9 & 0,0 & 2,4 & 1,5 & 0,22 & 7,0 & 59 \\
\hline 11 & 50 & 3.7 & 1,4 & 6,5 & 0,0 & 5,0 & 2,3 & 0,21 & 10,1 & 74 \\
\hline 12 & 44 & 4,3 & 7,1 & 6,2 & 0,0 & 4,1 & 1,8 & 0.07 & 10,5 & 57 \\
\hline 13 & 46 & 4,6 & 22,5 & 6,4 & 0.0 & 4,6 & 1,8 & 0,41 & 9,9 & 69 \\
\hline 14 & 24 & 3,0 & 2,0 & 6,5 & 0,0 & 3,5 & 1,3 & 0,08 & 6,7 & 73 \\
\hline 15 & 44 & 8,5 & 1,1 & 4,9 & 0,8 & 1,9 & 1,0 & 0,09 & 12,4 & 26 \\
\hline 16 & 36 & 7,5 & 2,4 & 4,8 & 1,0 & 1,4 & 0,7 & 0,10 & 11,6 & 19 \\
\hline 17 & 44 & 3,3 & 2,4 & 5,4 & 0,2 & 1,8 & 1,6 & 0,18 & 6,2 & 58 \\
\hline 18 & 45 & 4,3 & 4,5 & 5,0 & 0,9 & 1,3 & 0,5 & 0,12 & 7,5 & 25 \\
\hline 19 & 39 & 7,1 & 3,4 & 5,0 & 1,2 & 1,1 & 0,6 & 0,11 & 10,8 & 17 \\
\hline 20 & 46 & 3,8 & 21,2 & 6,0 & 0,0 & 3,8 & 1,5 & 0,31 & 9,3 & 60 \\
\hline 21 & 65 & 2,7 & 5,6 & 5,3 & 0,8 & 1,8 & 0,6 & 0,18 & 6,7 & 39 \\
\hline 22 & 62 & 4,9 & 4,9 & 5,5 & 0,2 & 3,3 & 1,0 & 0,22 & 9,3 & 48 \\
\hline 23 & 22 & 1,3 & 15,8 & 5,9 & 0,0 & 1,2 & 0,2 & 0,32 & 2,4 & 71 \\
\hline 24 & 40 & 2,1 & 12,6 & 5,4 & 0,4 & 1,1 & 0,3 & 0,44 & 3,8 & 47 \\
\hline 25 & 44 & 5,1 & 7,8 & 5,0 & 0,7 & 1,3 & 0,5 & 0,19 & 4,9 & 41 \\
\hline 26 & 25 & 2,6 & 20,6 & 5,6 & 0,1 & 2,9 & 0,5 & 0,31 & 5,9 & 63 \\
\hline
\end{tabular}




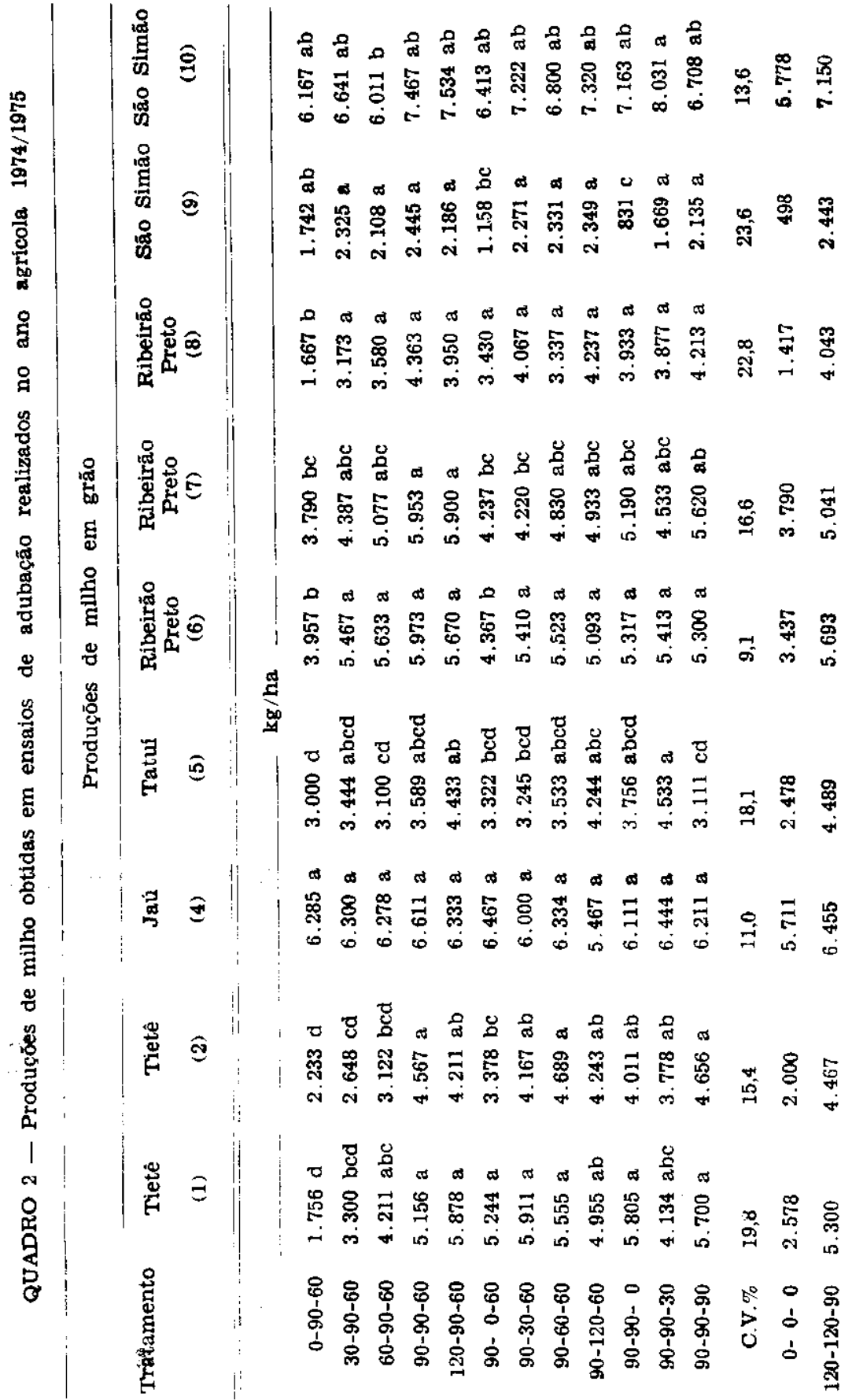




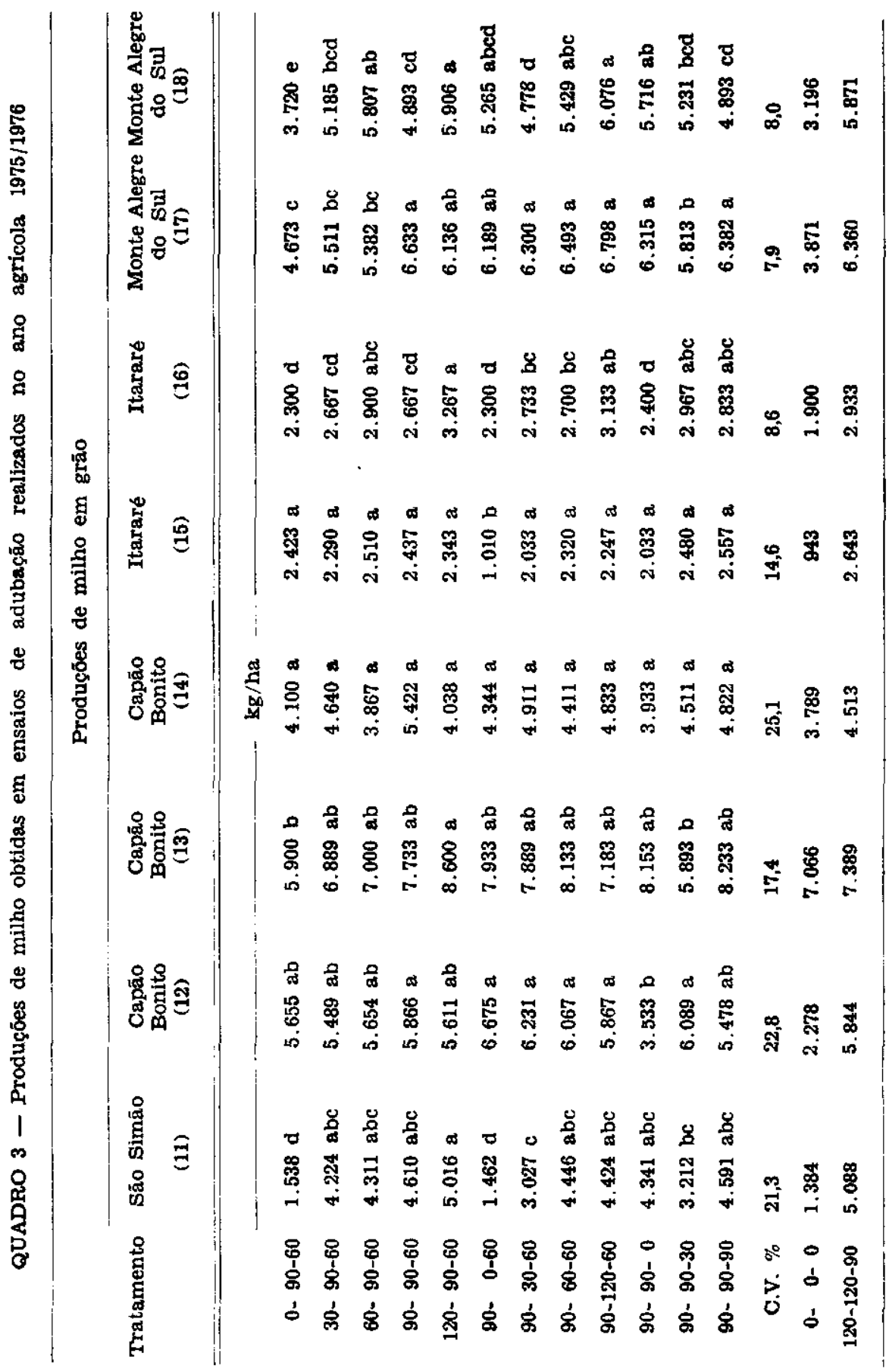


Comparando-se pelo teste de Duncan os tratamentos correspondentes à dose 0 de $\mathrm{N}, \mathrm{P}_{2} \mathrm{O}_{5}$ ou $\mathrm{K}_{2} \mathrm{O}$, tendo por base o tratamento comum às curvas de resposta, 90-90-60, nota-se que houve diferenças significativas para $\mathrm{N}$ em sete ensaios, para $\mathrm{P}_{2} \mathrm{O}_{5}$ em seis e para $\mathrm{K}_{2} \mathrm{O}$ em três experimentos.

Não se deve, contudo, concluir que na maioria dos casos não houve resposta à adubação química. A comparação dos tratamentos $0-0-0 \mathrm{com}$ 90-90-60 ou 120-120-90 mostra grande efeito $\mathrm{da}$ adubação química em quase todos os ensaios, embora o teste de Duncan não tenha sido aplicado nessas comparações.

Para os ensaios de 1975/76 (quadro 4), a comparação das médias pelo teste de Duncan revelou que, tomando por base o tratamento $10-80-50$ com $\mathrm{Zn}$ e 80 de $\mathrm{N}$ em cobertura, houve diferenças significativas em quatro casos para $\mathrm{N}$, um caso para $\mathrm{P}_{2} \mathrm{O}_{5}$ e nenhum caso para $\mathrm{K}_{2} \mathrm{O}$.

Quantitativamente, as respostas médias, para os dois grupos de ensaios, foram grandes para nitrogênio, intermediárias para fósforo e baixas para potássio. $O$ zinco não afetou a produção de milho e a cobertura tardia só em Tatuí (quadro 4). Por essa razão, esses tratamentos não serão mais discutidos.

Mais adiante, neste trabalho, é demonstrado como a análise de solo permite a separação de ensaios de maior ou menor resposta, para fósforo e potássio.

\subsection{Correlações entre respostas à adubação e parâmetros forne- cidos pela Análise de Solo.}

No quadro 5 são apresentados dados de algumas correlações mais importantes no que se refere àqueles parâmetros que vêm sendo utilizados na interpretação da análise de terra. Correlações com matéria orgânica, fósforo e potássio são também indicadas nas figuras 1,2 e 3 .

Cabe salientar a importância de utilizar nas correlações a resposta à adubação em termos de produção relativa, com o que são minimizados efeitos de diferenças de produtividade devidas a fatores limitantes que não nutrientes, principalmente os climáticos, nas correlaçôes com os resultados de análise de solo.

No caso do nitrogênio, não se obteve nenhuma correlação significativa entre a resposta a esse elemento e o teor de matéria orgânica revelado na análise de solo. A figura 1 mostra que a dispersão das respostas é bastante grande, havendo respostas importantes para solos com menos de $2 \%$ de matéria orgânica ou mais de 5\%. Da mesma forma, respostas insignificantes foram verificadas também para solos com teores de matéria orgânica entre 2 e mais de $8 \%$. Os teores de $\mathrm{P}$ e $\mathrm{K}$ também não apresentaram correlações com resposta a nitrogênio, como, aliás, seria de esperar. Não se confirmaram neste trabalho as sugestões de MIRANDA (15) e FUZATTO et alii (11) que sugeriram critérios de análise de solo para adubação nitrogenada.

Cabe mencionar que os métodos já em uso em outros países para nitrogênio, baseiam-se em princípios de análise bem específicos para o ele- 
Vol. 40 , Art. n. ${ }^{\circ} 6$

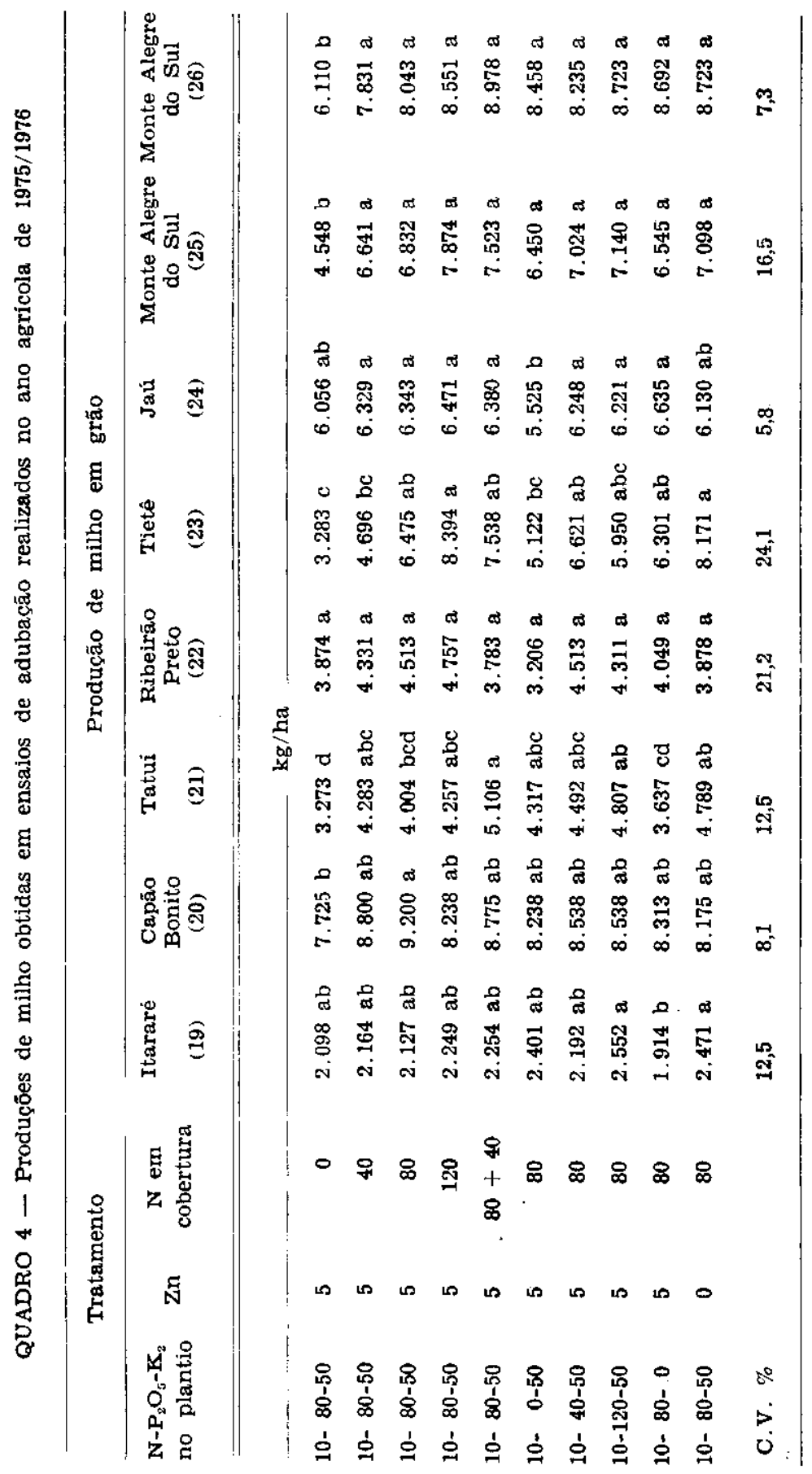


QUADRO 5 - Coeficientes de correlaçāo obtidos entre a resposta à adubaçäo com nitrogênio, fósforo e potássio, expressa em termos de produção relativa (y), e parâmetros de análise de solo

\begin{tabular}{|c|c|c|c|c|c|}
\hline \multirow{2}{*}{ Nutriente } & \multicolumn{2}{|c|}{ Correlaçấo simples } & \multicolumn{3}{|c|}{ Correlaçắa múltipla } \\
\hline & $\mathrm{x}$ & $\mathbf{r}$ & $\mathbf{x}_{1}$ & $x_{1}$ & $\mathbf{R}$ \\
\hline \multirow[t]{3}{*}{ Nitrogênio } & M.O. & 0,349 n.s. & & & \\
\hline & $\mathbf{P}$ & 0,097 n.s. & & & \\
\hline & $\mathbf{K}$ & $-0,041$ n.s. & & & \\
\hline \multirow[t]{4}{*}{ Fósforo } & $\mathbf{P}$ & $0,428^{*}$ & & & \\
\hline & $1 / \mathbf{P}$ & $-0,717^{* *}$ & $1 / \mathrm{P}$ & M.O. & $-0,754^{* *}$ \\
\hline & & & $1 / P$ & $\mathrm{pH}$ & $-0,750^{* *}$ \\
\hline & & & $1 / \mathrm{P}$ & Argila & $-0,768 * *$ \\
\hline \multirow[t]{4}{*}{ Potássio } & $\mathbf{K}$ & $0,543^{* *}$ & & & \\
\hline & $1 / K$ & $-0,712^{* *}$ & $1 / \mathrm{K}$ & $(\mathrm{Ca}+\mathrm{Mg}) / \mathrm{K}$ & $-0,713^{* *}$ \\
\hline & 1/Sat. $\mathbf{K}($ (') & $-0,478$ & & & \\
\hline & $(\mathrm{Ca}+\mathrm{Mg}) / \mathrm{K}$ & $-0,497$ & & & \\
\hline
\end{tabular}

(1) Sat. $\mathbf{K}$ - Saturaçāo de $\mathbf{K}$ em relaçāo à capacidade de troca de catíons.

mento no solo. Assim, são determinados teores de nitrato e amônio no solo, ou as quantidades desses ions liberados por incubação (32). O nitrogênio, sendó um elemento móvel no solo, tem um comportamento pouco elástico, significando que, em condiçõcs de deficiência, estas podem ser muito graves. Ademais, ainda por causa da mobilidade do elemento, além das variações que ocorrem nas quantidades liberadas da matéria orgânica por mineralização durante o ciclo das culturas, a resposta a nitrogênio pode ser bastante variável. Cri térios empíricos para nitrogênio têm sido utilizados, mas, em geral, sem uma comprovação objetiva de sua eficiência. Os métodos com base científica ainda não foram testados em São Paulo com suficiente profundidade.
No caso do fósforo e do potássio, houve correlações significativas entre as produções relativas e as recíprocas dos teores dos elementos no solo (quadro 5). A equação utilizada, $\mathrm{Y}=\mathrm{a}+\mathrm{b} / \mathrm{x}$, ilustrada nas figuras 2 e 3 , foi a que melhor se ajustou aos resultados experimentais, tendo sido comparada com outras equações, entre elas a do $2 .^{\circ}$ grau, a logarítmica, a exponencial e a raiz quadrada.

Para o caso do fósforo, a consideração da matéria orgânica, do $\mathrm{pH}$ ou do teor de argila permitiu uma pequena melhoria nos coeficientes de correlação. Já para potássio, não houve alteração pela consideração de outros parâmetros, além do teor de potássio. As correlaçōes com $\mathrm{P}$ ou $\mathrm{K}$ no solo confirmam as obtidas em outros trabalhos $(7,13,20,21,29)$, in- 


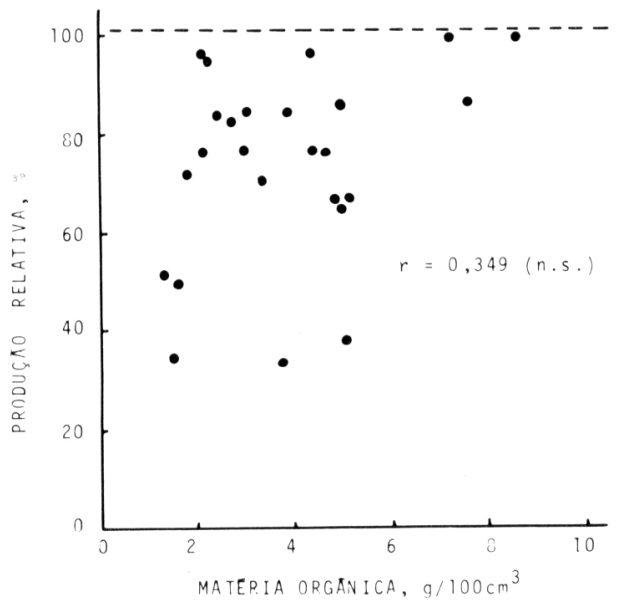

Figura 1. - Relação entre os teores de matéria orgànica do solo e as respostas a nitrogetnio, expressas em porcentagem do máximo.

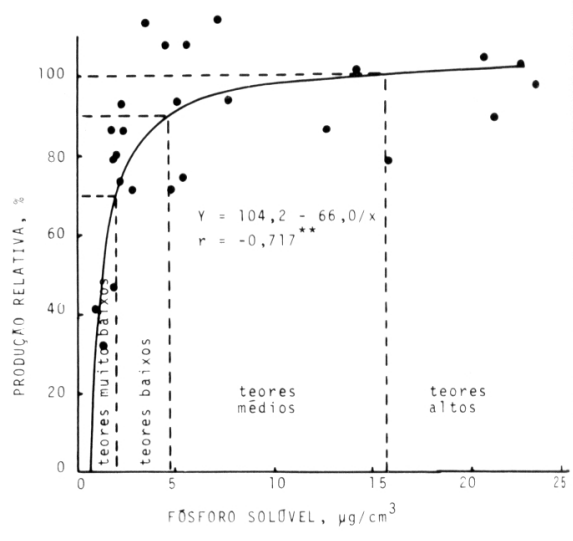

Figura 2. - Relaşżo entre teores de fósforo solúvel no solo e respostas à adubaçăo fosfatada, expressas em porcenta. gem da produçáo máxima. e estabelecimento de classes de teores de fósforo no solo.

dicando que a determinação desses dois elementos é um teste válido para diagnosticar seu estado de carência em solos. Já para os demais critérios testados e utilizados em outros trabalhos $(3,8,9,10,11,12,13,26$, $27,30,31$ ), é difícil uma comparação, pois, freqüentemente, quando têm sido usados vários critérios de interpretação, a utilização tem sido feita em conjunto, não sendo possível avaliar a importância isolada de cada um deles.

Nos casos de fósforo e potássio, o coeficiente de determinação $\left(\mathrm{r}^{2}\right)$ foi da ordem de 0,50 , ou seja, $50 \%$ da resposta esteve associada à correlação estabelecida. Deve-se lembrar que ensaios de campo ainda têm baixa precisão em nossas condições de trabalho, principalmente a adubação potássica, afetando de modo irregular as respostas. Às vezes, alguns pontos discrepantes podem prejudicar bas-
Figuta 3. - Relação entre teores de potássio trocável no solo e respostas à adubas zo fosfatada, expressas $\mathrm{cm}$ porcen. tagem da produçăo máxima, e estabelecimento de classes de teores de potźssio no solo. 
tante os coeficientes de determinação. Assim, por exemplo, se no caso do potássio forem excluídos os pontos de números 18 e 23 dos cálculos, o coeficiente de determinação passa a 0,71 . Da mesma forma, excluindo os pontos dos ensaios 19 e 23 , no caso do fósforo, o coeficiente de determinação passa a 0,60 . Além disso, as figuras 2 e 3 mostram que houve poucos ensaios com teores muito baixos e mesmo baixos. Quando a distribuição de pontos é melhor em vários níveis de resposta, o coeficiente de determinação pode ser bem mais elevado (13). Esses exemplos mostram que, possivelmente, possa ser feito progresso em estudos de correlação entre respostas a ensaios de adubação e parâmetros dados pela análise de solo, se forem tomadas medidas efetivas para melhorar a precisão dos ensaios e os problemas forem estudados dentro de grande amplitude de variação de valores.

\subsection{Curvas de resposta e eficiên- cia fertilizante dos nutrientes}

Com as curvas apresentadas nas figuras 2 e 3 , é possível delimitar classes de teores dos nutrientes no solo, conforme indicado. Os limites superiores, em termos de produção relativa, que delimitam as classes, são $70 \%$ para teores muito baixos, $90 \%$ para teores baixos e $100 \%$ para teores médios.

Após estabelecidas as classes, os ensaios foram separados segundo os teores de $\mathbf{P}$ e $\mathbf{K}$ nos solos. Foram calculadas as curvas de resposta a fósforo ou potássio, para cada grupo de ensaios, ajustando aos resultados experimentais a equação do $2 .^{\circ}$ grau. As curvas são apresentadas na figura 4, lado esquerdo. Para nitrogênio, é apresentada uma única curva, visto que não tendo sido significativa a correlação entre resposta a esse elemento e a análise de solo, não foi possível separar os ensaios com base na análise de terra.

Essas curvas mostram que a análise de terra pode ser usada para discriminar as respostas à adubação para fósforo e potássio, partindo de um critério simples de interpretação.

Ainda na figura 4, é apresentada a eficiência fertilizante dos nutrientes, expressa em quilograma de milho por quilograma do nutriente considerado. As retas apresentadas representam as derivadas das equações do $2 .^{\circ}$ grau das curvas de resposta: elas dão de imediato o retorno, em termos de milho, que se pode conseguir pela aplicação dos nutrientes. Embora não seja o objetivo deste trabalho fazer considerações de ordem econômica, é conveniente mencionar que, entrando na ordenada da figura com relação de preços de nutriente para produto, obtém-se pelo gráfico a dose mais econômica diretamente da abscissa.

No caso da interpretação da análise de solo para fósforo, convém ressaltar o tipo de curva ajustada (figura 2), que apresenta uma queda brusca em uma faixa muito estreita para teores muito baixos, dando um limite superior para essa classe de $2 \mu \mathrm{g} / \mathrm{cm}^{3}$. Para soja, esse limite foi de $3 \mu \mathrm{g} / \mathrm{cm}^{3}(21)$ e, para cana-de-açúcar, de $4 \mu \mathrm{g} / \mathrm{cm}^{3}(13)$. Como é apenas nessa classe de teores que são esperadas as respostas muito elevadas ao elemento, talvez este seja um dos problemas da falta de confiança no método de análise de $P$, que era utilizado com limites de interpretação bem mais elevados no passado $(4,5)$. 

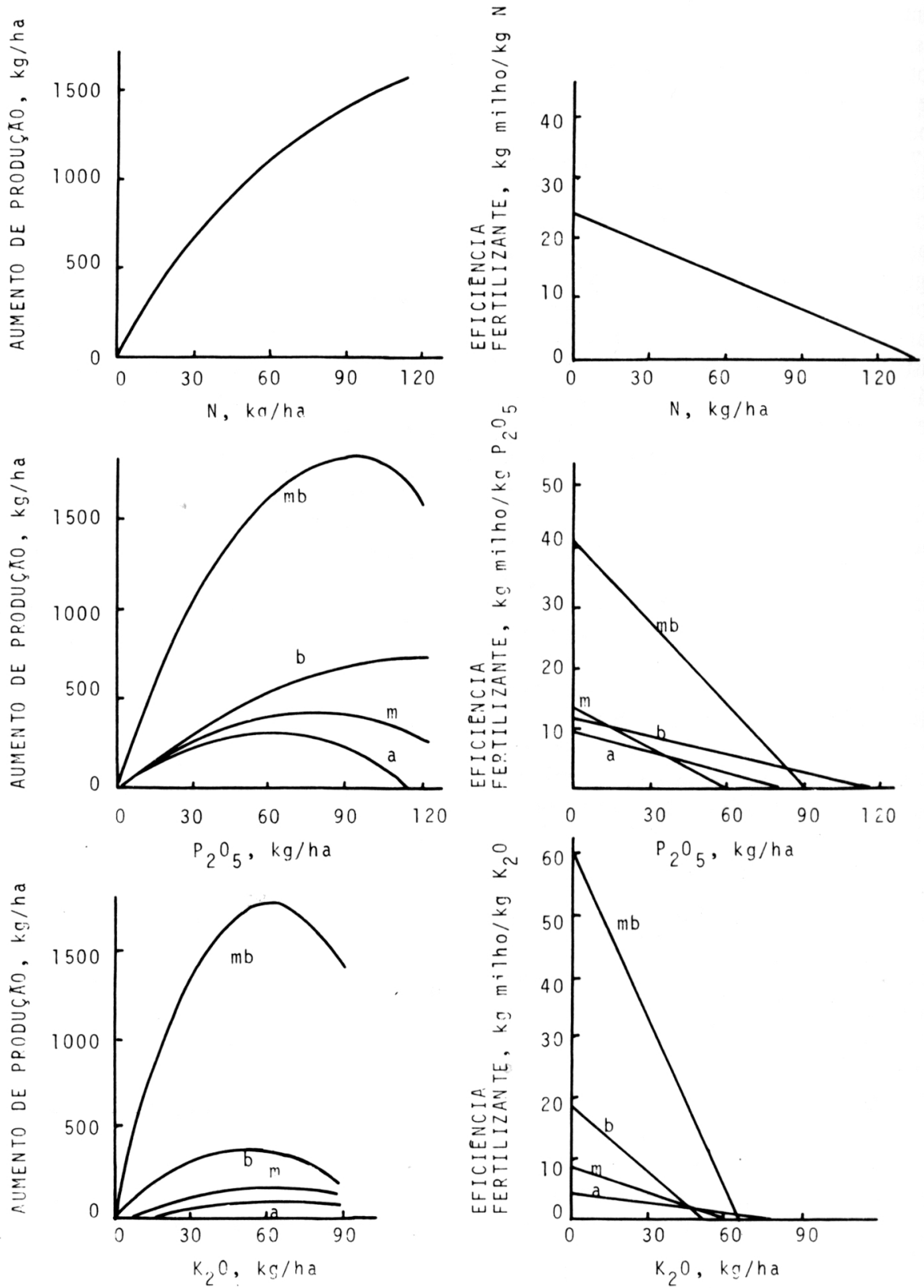

Figura 4. - Curvas de respostas de milho a $N, \mathrm{P}_{2} \mathrm{O}_{3}$ e eficiència fertilizante dos trés nutrientes. As lettas mb, b. m e a representam res pectivamente teores muito baixos. baixus. médios e altos de fósfoto ou potássio no solo 
Para potássio, embora o tipo de curva apresente as mesmas características que a de fósforo, os limites estão mais de acordo com os previamente considerados $(4,5)$.

Tanto no caso do fósforo como do potássio, as curvas de correlação para teores no solo estão de acordo com o comportamento elástico dos dois elementos (2), esperando-se que, mesmo quando ocorra a deficiência, produções elevadas possam ser obtidas $e$, somente quando a deficiência é extrema e os teores no solo muito baixos, a falta do nutriente no solo passe a limitar severamente a produção.

Quanto às respostas à adubação, cabe ressaltar a diferença de comportamento dos três nutrientes. Enquanto - nitrogênio apresenta uma curva crescente para $120 \mathrm{~kg} / \mathrm{ha}$, no caso do fósforo e muito mais no do potássio, já ocorrem efeitos depnessivos dentro dos níveis testados. E provável que parte desse efeito seja decorrente da maneira localizada de aplicação dos adubos.

SOIL TESTING APPLIED TO ESTIMATE CORN RESPONSES TO FERTILIZATION

\section{SUMMARY}

In this paper some of the criteria that have been used in the State of Sâo Paulo in soil test interpretation were studied, correlating soil test parameters with corn response to applied nitrogen, phosphorus or potassium in 25 field experiments.

Exchangeable potassium and phosphorus soluble in $0.05 \mathrm{~N} \mathrm{H}_{2} \mathrm{SO}$, correlated well with responses of the crop to the applied nutrients. Nitrogen responses could not be correlated to soil test values.

Response curves and fertilizer efficiencies are presented for nitrogen, phosphorus and potassium. For the two last nutrients, the average curves are given for very low, low, medium and high soil test values.

\section{REFERENCIAS BIBLIOGRAFICAS}

1. BRASIL. SERVIÇO NACIONAL DE PESQUISAS AGRONOMICAS. Comissão de Solos. Levantamento de reconhecimento dos solos do Estado de Sảo Paulo. Rio de Janeiro, Ministério da Agricultura, 1960. 634p. (Boletim, 12)

2. BRAY, R. H. Correlation of soil tests with crops response to added fertilizers and with fertilizer requirement. In: KITCHEN, H. B., ed. Diagnostic techniques for soils and crops. Washington, American Potash Institute, 1948. p.53-86.

3. CAMARGo, A. P. Niveis de calagem e de adubaçāo nitrogenada e fosfatada para milho. Piracicaba, 1979. 84f. (Tese de doutoramento - ESALQ)

4. CATANI, R. A.; GALLO J. R.; GARGANTINI, H. Amostragem de solo, métodos de análises, interpretação e indicaçōes gerais para fins de fertilidade. Campinas, Instituto Agronômico, 1955. 29p. (Boletim. 69)

5. CATE JR., R. B. \& NELSON, L. A. A rapid method for correlation of soil test analysis with plant response data. Raleigh, North Carolina State University, Agric. Exp. Sta., 1965. 66p. (Intern. Soil Testing Series. Tech. Bull. 1)

6. FITTZ, J. W. \& NELSON, W. L. The determination of lime and fertilizer requirements of soils through chemical tests. Adv. Agron., 8:241-282, 1956. 
Vol. 40, Art. n. ${ }^{\circ} 6$

7. FRETTAS, L. M. M.; McCLUNG, A. C.; GOMDS, F. P. Determinação das áreas deficientes em potássio para a cultura de algodão. Fertilité, 26:37-47, 1966.

8. FUZATTO, M. G. \& CAVALERI, P. A. Correlação entre a resposta do algodoeiro a adubação fosfatada e a análise química do solo, nas condiçóes do Estado de São Paulo. Bragantia, Campinas, 25:407-420, 1966.

9. \& FERRAZ, C. A. M. Correlaçäo entre a resposta do algodoeiro e a porcentagem de saturação em bases ein vários tịpos de solos do Estado de São Paulo. Bragantia, Campinas, 25:237-240, 1966.

10. FUzATTO, M. G. \& FERRAZ, C. A. M. Correlaçāo entre o efeito da adubaçāo potássica no algodoeiro e análise químtea do solo. Bragantia, Campinas, 26 :345-352, 1967.

11. - VENTURINI, W. R.; CAVALERI, P. A. Estudo técnico-económico da adubação do algodoeiro no Estado de Sảo Paulo. Campinas, Instituto Agronómico, 1970. 15p. (Projeto BNDE/ANDA/CIA. Boletim, 1)

12. MASCARENHAS, H. A. A.; DEMATTE, J, D.; MIYASAKA, S.; IGUE, T. Estudos preliminares sobre a adubaçäo econômica de soja (Glycine max (L.) Merrill), na região da Alta Mogiana, em latosol roxo e latosol vermelho-escuro, fase arenosa. Campinas, Instituto Agronômico, 1971. 7p. (Projeto BNDE/ANDA/CLA. Boletim, 3)

13. MARINHO, M. L. \& ALBUQUERQUE, G. A. C. Calibration of extractable phosphorus is soils for sugarcane in Alagoas, Brazil. In: CONGR. INTERN. SOC. SUGAR CANE TECHNOLOGISTS, 16., São Paulo, Brasil, 1977. Proceedings. p.1283-1292.

14. MIRANDA, L. E. C. \& JORGE, J. P. N. Adubação do milho. II - Comprovação da eficiência das fórmulas de adubaçăo recomendadas em função da análise do solo. Campinas, Instituto Agronômico, 1971. 12p. (Projeto BNDE/ANDA/CIA. Boletim, 12)

15. MrRANDA, L. T. Adubação do milho. I - Relaçăo entre dados de ensaios de campo e de análise química do solo. Campinas, Instituto Agronômíco, 1971. 11p. (Projeto BNDE/ANDA/CIA. Boletim, 11)

16. - ; ALMEIDA, T. C.; COELFO, F. A. S.; MIRANDA, L. E. C. Adubação do milho. III - Comprovaçāo da eficiência de tabelas de recomendação de adubaçäo, em campos de demonstração. Campinas, Instituto Agronômico, 1971. 7p. (Projeto BNDE/ANDA/CIA. Boletim, 13)

17. MIRANDA, L. E. C. \& MIRANDA, L. T. Adubaçäo do milho. IV - Estudo econômico de adubação de milho no Estado de Såo Paulo. Campinas, Instituto Agronômico, 1971. 14p. (Projeto BNDE/ANDA/CIA. Boletim, 14)

18. OLIVEIRA, J. B. \& MONIZ, A. C. Levantamento pedológico detalhado da Estaçăo Experimental de Ribeirāo Preto, SP. Bragantia, Campinas, 34:59-113, 1973.

19. - VALADARES, J. M. A. S.; ROTTA, C. L. Levantamento pedológico detalhado da Estaçāo Experimental de Itararé, SP. Bragantia, Campinas, $35: 295-333,1976$.

20. RAIJ, B. van. Calibraçảo do potássio trocável em solos para feijão, algodão e cana-de-açúcar. Ciência e Cultura, são Paulo, 26:575-579, 1974.

21. \& MASCARENHAS, H. A. A. Calibraçâo de potássio e fósforo em solos para soja. In: CONGRESSO BRASILEIRO DE CIENCIA DO SOLO. 15.. Campinas. 1976. Anais. p.309-315.

22. \& ZULLO. M. A. T. Métodos de análises de solo para fins de fertilidade. Campinas. Instituto Agronómico, 1977. 16p. (Circular, 63) 
23. RIS, J. \& IUIT, B. van. The establishment of fertilizer recommendations on the basis of soil tests. Haren, Grouningen, Holanda, Instituut voor Bodemvruchtbaarheid, 1973. 52p.

24. ROTTA, C. L.; JORGE, J. A.; OLIVEIRA, J. B.; KUPPER, A. Levantamento pedológico detalhado da Estaçāo Experimental de Monte Alegre do Sul, SP. Bragantia, Campinas, 30:215-276, 1971.

25. ROUSE, R. D. Soll test theory and calibration for cotton, corn, soybeans and coastal bermudagrass. Auburn, Alabama, Agric. Exp. Station, 1968. 67p. (Bulletin, 375)

26. SILVA, N. M. Importáncia da seleção de glebas para estudos de adubaçāo do algodoeiro. Campinas, Instituto Agronómico, 1971. 11p. (Projeto BNDE/ANDA/CIA. Boletim, 8)

27. -; FUZATTO, M. G.; FERRAZ, C. A. M.; GRIDI-PAPP, I. L.; CIA, E.; IGUE, T.; CAVALERI, P. A. Estudo técnico-economico de recentes experimentos de adubaçāo do algodoeiro. Campinas, Instituto Agronômico, 1971. 11p. (Projeto BNDE/ANDA/CIA. Boletim, 7)

28. SNEDECOR, G. W. \& COCHRAN, W. G. Statistical methods, 6.ed. Ames, Iowa State University Press, 1976. 593p.

29. VERDADE. F. C.; VENTURINI, W. R.; AMARAL, A. Z.; WUTKE, A. C. P. Niveis de fertilidade do solo para a cultura algodoeira. II - Correlaçẩo entre a produçāo e o teor de fósforo no solo. Bragantia, Campinas, 25:41-55, 1966.

30. - WUTKE, A. C. P.; AMARAL, A. Z.; IGUE, K. Níveis de fertilidade dos solos do Estado de Sâo Paulo para a cultura algodoeira. I - Os teores de fósforo, nitrogênio e potássio. Bragantia, Campinas, 24:55-74, 1965.

31. VIDOR, C. \& FREIRE, J. R. J. Calibraçåo de análise de solo para a cultura da soja. Agronomia Sulriograndense, 7:63-72, 1971.

32. WALSH, L. \& BEATON, J. D., ed. Soil testing and plant analysis. Madison, Soll Sci. Amer., 1973. 491p. 